\title{
SISTEMÁTICA DE Rhabdepyris KIEFFER (HYMENOPTERA, BETHYLIDAE) AMAZÔNICOS COM ANTENAS PECTINADAS
}

\author{
Adriano da S. MAGESKY ${ }^{1}$, Celso Oliveira AZEVEDO'
}

RESUMO - São descritas e ilustradas Rhabdepyris opistolatus sp. nov., $R$. longimerus sp. nov., $R$. pleurorrectus sp. nov., $R$. latimerus $\mathrm{sp}$. nov. e $R$. pectinatus sp. nov, com antenas pectinadas da floresta amazônica brasileira.

Palavras-chave: Rhabdepyris, Bethylidae, Hymenoptera, Brasil, antena pectinada.

Systematic of the Amazon Rhabdepyris Kieffer (Hymenoptera, Bethylidae), with Ramose Antennae.

ABSTRACT - Rhabdepyris opistolatus $\mathrm{sp}$. nov., $R$. longimerus $\mathrm{sp}$. nov., $R$. pleurorrectus $\mathrm{sp}$. nov., $R$. latimerus sp. nov. and $R$. pectinatus sp. nov. with ramose antennae from Brazilian Amazon rainforest are described and illustrated.

Key words: Rhabdepyris, Bethylidae, Hymenoptera, Brazil, ramose antennae.

Rhabdepyris Kieffer, 1904 é um dos mais importantes gêneros de Epyrini, com cerca de 110 espécies no mundo (Azevedo, 1999). Vargas-Rojas (2001) descreveu as duas primeiras espécies do gênero com antenas pectinadas, ambas da floresta amazônica colombiana. Neste estudo, descrevemos mais cinco espécies novas de Rhabdepyris com antena pectinadas da floresta amazônica, cujos processos pectinados podem ser desde quase duas vezes maiores do que o comprimento dos segmentos, como em $R$. opistolatus sp. nov., até sendo uma projeção pequena, como em $R$, pleurorrectus $\mathrm{sp}$. nov.

Estas espécies pertencem ao grupo viridissimus do subgênero Chlorepyris, por terem cabeça larga, fóvea inferior da mesopleura alongada e inserção das antenas quase ao nível da margem inferior dos olhos.
O material examinado pertence à Coleção Entomológica do Instituto Nacional de Pesquisas da Amazônia (INPA). A nomenclatura adotada neste estudo, de modo geral, segue Evans (1965), e as abreviaturas das medidas e indices utilizados foram: comprimento da asa anterior (LFW); comprimento da cabeça (LH); largura da cabeça (WH); largura da fronte (WF); comprimento do olho (HE); linha ocelar-ocular (OOL); largura do triângulo ocelar (WOT); diâmetro do ocelo anterior (DAO); linha vértice-ocular (VOL). A nomenclatura do integumento segue Harris (1979).

\section{Rhabdepyris (Chlorepyris)} opistolatus sp. nov.

(Figs. 1, 6, 11, 16, 21-22)

Descrição. Macho: comprimento do corpo $5,76 \mathrm{~mm}$, LFW 2,48 mm.

Cor: cabeça e tórax verde-

\footnotetext{
'Universidade Federal do Espírito Santo, Departamento de Biologia, Av. Marechal Campos 1468, Maruípe,29.040-090, Vitória, ES, Brasil. (adsmagesky@bol.com.br, cazevedo@npd.ufes.br).
} 
metálicos, propódeo e metasomo pretos; palpos, antenas e mandibulas castanho-claros, clipeo preto; pernas castanhas, com coxas pretas, fêmures posteriores enfuscados, asas hialinas.

Cabeça (Fig. 1): mandibulas com cinco dentes apicais, o ventral mais agudo e muito maior que os demais. Clípeo curto, com carena mediana completa, ligeiramente convexa em perfil. Razão entre os quatro primeiros segmentos antenais de 20:9:7:11; segmentos antenais VI-XII com processos finos, retos, muito desenvolvidos, que nascem na face externa da porção distal dos segmentos, maiores nos segmentos VII-XII, onde são 1,25 x mais longos do que o próprio segmento (segmento IX); processos pectinados dos segmentos VII-X de mesmo tamanho, segmentos XI-XII um pouco menores (segmento XII 0,66 x mais longo do que o segmento XI). Fronte muito fracamente coriácea, brilhante, com pontuações pequenas e esparsas. WH $1,11 \times$ LH, WF 0,66 x WH, WF 1,29 $x$ HE, OOL 1,13 x WOT, ângulo frontal do triângulo ocelar obtuso, ocelo posterior distante da crista do vértice $1,1 \times$ DAO. Vértice reto, com cantos arredondados. VOL $0,23 \times$ HE.

Mesosomo: dorso torácico fracamente coriáceo, com pontuações pequenas e distantes; notáulices completas, arqueadas medianamente, convergentes e largas atrás, distantes uma da outra atrás $1,0 \times$ suas larguras; sulcos parapsidais evidentes, incompletos anteriormente; sulcos escutelares profundos, extremidades dilatadas, arredondadas e arqueadas para trás (Fig. 6). Disco propodeal
$1,15 \mathrm{x}$ mais largo que longo, com três carenas discais fortes, carena mediana completa, carenas paramedianas convergentes atrás, atingindo a carena mediana, espaços entre as carenas discais com estrias; parte posterior do disco com estrias longitudinais curtas, ângulo posterior foveolado, disco côncavo em perfil, parte lateral com uma fóvea alongada, 5,0 $\mathrm{x}$ mais longa que larga, canto posterior foveolado; declividade do propódeo com carena mediana, estriada, mais forte inferiormente; lateral do propódeo com estrias fortes (Fig. 11). Mesopleura polida, reta vista de cima, fóvea inferior grande, um tanto rasa, aberta atrás, com margem superior reta (Fig. 16). Pleurosterno separado da mesopleura por uma fóvea alongada. Fêmures anterior e mediano $2,3 \mathrm{x}$ mais longos que largos. Garras tarsais trífidas, o primeiro dente largo e arredondado, o segundo truncado e o terceiro curvo e pontiagudo.

Metasomo: polido e brilhante. Hipopigio com espinho mediano 0,32 $\mathrm{x}$ seu comprimento, margem posterior ligeiramente côncava. Genitália (Figs. 21-22): parâmero com ápice um pouco inclinado para dentro, arredondado, margens ventral e dorsal retas, base desenvolvida e arredondada; volsela com cúspide mais alta que o parâmero, reta e de ápice arredondado; digito mais curto que a cúspide; edeago em forma de garrafa, com base arredondada, na mesma altura do dígito; apodema com base dilatada.

Material examinado. Holótipo: macho, BRASIL, Amazonas, Manaus, Reserva Campina, 19.VI.1992, armadilha adesiva, $3 \mathrm{~m}$, J. Vidal \& J. 
Vidal col. (INPA).

Observação: esta espécie é conhecida apenas a partir do holótipo.

Etimologia: nome refere-se à notáulice larga atrás.

\section{Rhabdepyris (Chlorepyris) longimerus sp. nov.}

(Figs. 2, 7, 12, 17, 23-24)

Descrição. Macho: comprimento do corpo 3,94 mm; LFW 1,92 mm.

Cor: corpo preto; palpos, antenas e mandíbulas castanho-claros, clipeo preto; pernas castanho-escuras, com coxas pretas, asas hialinas.

Cabeça (Fig. 2): mandíbulas com cinco dentes apicais, o ventral mais agudo e maior que os demais. Clípeo curto, angulado, com carena mediana completa, reto de perfil. Razão entre os quatro primeiros segmentos antenais de 18:9:5:8, segmentos antenais VII-XII com processos muito curtos, cônicos, que nascem na face externa da porção distal dos segmentos, aproximadamente de mesmo tamanho, $0,5 \times$ tão longos quanto os próprios segmentos (segmento IX). Fronte pouco coriácea, brilhante, com pontuações pequenas e esparsas. WH $1,15 \times$ LH, WF $0,69 \times$ WH, WF $1,4 \times$ HE, OOL $0,8 \times$ WOT, ângulo frontal do triângulo ocelar obtuso, ocelo posterior distante da crista do vértice $0,4 \times$ DAO. Vértice reto, com cantos arredondados. VOL $0,13 \times$ HE.

Mesosomo: dorso torácico pouco coriáceo; notáulices completas, quase retas, largas e muito convergentes atrás, distantes uma da outra atrás 1,0 $\mathrm{x}$ suas larguras; sulcos parapsidais finos e retos, ausentes no terço anterior; sulcos escutelares profundos, extremidades arqueadas para trás (Fig. 7). Disco propodeal $1,23 \times$ mais largo que longo, com cinco carenas discais fortes, carena mediana completa, carenas paramedianas convergentes atrás, atingindo a carena mediana, espaços entre as carenas discais com estrias; parte posterior do disco com estrias longitudinais, ângulo posterior foveolado, disco côncavo em perfil, parte lateral com fóvea estriada, alongada, 3,0x mais longa que espessa; declividade do propódeo polida, com carena mediana; lateral do propódeo com estrias fortes (Fig. 12). Mesopleura polida e brilhante, pouco globosa vista de cima, fóvea inferior grande, profunda, aberta atrás (Fig. 17). Pleurosterno separado da mesopleura por uma fóvea alongada. Fêmures mediano e anterior 2,0 $\mathrm{x}$ mais longos que largos. Garras tarsais trifidas, o primeiro dente largo e arredondado, o segundo truncado e o terceiro curvo e pontiagudo.

Metasomo: polido e brilhante. Genitália (Figs. 23-24): parâmero alongado, ápice inclinado, quase reto, com o canto ventral angulado, margens ventral e dorsal quase retas, base inclinada, mais estreita do que o ápice, curva ventralmente; volsela com cúspide mais baixa do que o parâmero, reta, com ápice arredondado; dígito curvo mais curto que a cúspide; edeago em forma de garrafa, na mesma altura do dígito, base arredondada, angulada medianamente; apódema com base pouco dilatada. 
Material examinado. Holótipo: macho, BRASIL, Amazonas, Manaus, Reserva Ducke, 17.VII.1992, armadilha adesiva, $2 \mathrm{~m}$, J. Vidal \& J. Vidal col. (INPA).

Observação: esta espécie é conhecida apenas a partir do holótipo, que teve seu hipopígio perdido.

Etimologia: nome refere-se ao parâmero longo.

\section{Rhabdepyris (Chlorepyris) pleurorrectus sp. nov.}

(Figs. 3, 8, 13, 18, 25-26)

Descrição. Macho: comprimento do corpo 4,82 mm, LFW 2,20 mm.

Cor: corpo preto; palpos, antenas e mandíbulas castanho-claros, clipeo preto; pernas castanho-escuras, com coxas pretas, asas hialinas.

Cabeça (Fig. 3): mandibulas com cinco dentes apicais, o ventral mais agudo e muito maior que os demais. Clípeo curto, com carena mediana completa, reto de perfil. Razão entre os quatro primeiros segmentos antenais de 20:10:5:10; segmentos antenais VII-XI com processos curtos, um tanto cônicos que nascem na face externa da porção distal dos segmentos, aproximadamente de mesmo tamanho e $0,16 \times$ tão longos que os próprios segmentos (segmento IX); bases dos segmentos VII-XII aumentando progressivamente de tamanho. Fronte fracamente coriácea, brilhante, com pontuações pequenas $\mathrm{e}$ esparsas. WH $1,18 \times$ LH, WF $0,69 \times$ WH, WF $1,39 \times$ HE, OOL $0,82 \times$ WOT, ângulo frontal do triângulo ocelar obtuso, ocelo posterior distante da crista do vértice 0,33 $\mathrm{x}$ DAO. Vértice reto, com cantos arredondados. VOL $0,06 \times \mathrm{HE}$.

Mesosomo: dorso torácico coriáceo; notáulices completas, retas, convergentes e largas atrás, distantes uma da outra atrás $2,0 \mathrm{x}$ suas larguras; sulcos parapsidais finos e retos, ausentes no terço anterior; sulcos escutelares profundos, extremidades arqueadas para trás (Fig. 8). Disco propodeal 1,37 $\mathrm{x}$ mais largo que longo, com cinco carenas discais fortes, carena mediana completa, carenas paramedianas convergentes atrás, atingindo a carena mediana; espaços entre carenas discais com estrias; parte posterior do disco com estrias longitudinais curtas, ângulo posterior foveolado, disco côncavo em perfil com fóvea estriada, alongada, $2,0 \times$ mais longa que larga; declividade do propódeo com carena mediana, ligeiramente estriada; lateral do propódeo com estrias longitudinais fortes (Fig. 13). Mesopleura reta vista de cima, polida, fóvea inferior aberta atrás, rasa (Fig. 18). Pleurosterno com fóvea longa, rasa, de margens definidas. Fêmures anterior e mediano $2,1 \times$ mais longos que largos. Garras tarsais trifidas, o primeiro dente largo e arredondado, o segundo truncado e o terceiro curvo e pontiagudo.

Metasomo: polido e brilhante. Hipopígio com espinho mediano 0,55 $\mathrm{x}$ seu comprimento, margem posterior estreita e com uma cova mediana profunda. Genitália (Figs. 25-26): parâmero com ápice inclinado, com canto ventral angulado, margens ventral e dorsal retas, base desenvolvida e curva; volsela com cúspide menor que o parâmero, reta, com ápice arredondado; dígito mais curto que a cúspide; edeago reto, base ligeiramente angulada, mais baixo do 
que o digito; apodema com base um pouco dilatada.

Material examinado. Holótipo: macho, BRASIL, Amazonas, Manaus, Reserva Campina, 08-19.VI.1992, armadilha adesiva, J.Vidal \& J.Vidal col. (INPA). Parátipo: 1 macho, BRASIL, Amazonas, Manaus, Reserva Campina, 08-19.VI.1992, armadilha adesiva, J.Vidal \& J.Vidal col. (INPA).

Variações. WH 1,28 x LH; WF $0,68 \times$ WH; WF $1,44 \times$ HE; disco propodeal $1,5 \times$ mais largo que longo; fêmur anterior 2,22 x mais longo que largo; segmentos antenais com processos pectinados um pouco maiores onde são $0,29 \times$ menos longos que o próprio segmento (segmento IX).

Etimologia: nome refere-se à mesopleura reta em vista dorsal.

\section{Rhabdepyris (Chlorepyris) latimerus sp. nov.}

(Figs. 4, 9, 14, 19, 27-28)

Descrição. Macho: comprimento do corpo 4,94 mm, LFW 2,48 mm.

Cor: corpo preto; palpos, mandíbulas e antenas castanho-claros, clípeo preto; pernas castanho-escuras, com coxas pretas, asas hialinas.

Cabeça (Fig. 4): mandíbulas com cinco dentes apicais, o ventral mais agudo e muito maior que os demais. Clípeo curto, com carena mediana completa, reto de perfil. Razão entre os quatro primeiros segmentos antenais de 18:13:8:13; segmentos antenais VI-XII com processos antenais pouco desenvolvidos, que nascem na face externa da porção distal dos segmentos e são maiores nos segmentos medianos (segmentos VII-
IX), $0,66 \mathrm{x}$ tão longos quanto o próprio segmento (segmento IX); processos pectinados dos segmentos VII-IX progressivamente maiores assim como seus próprios comprimentos. Fronte coriácea, brilhante, com pontuações pequenas e distantes 1-2 x seus diâmetros. WH $1,23 \times \mathrm{LH}$, WF $0,69 \times \mathrm{WH}$, WF 1,26 $x$ HE, OOL 0,84 x WOT, ângulo frontal do triângulo ocelar obtuso, distância do topo do olho à crista do vértice $0,31 \times \mathrm{DAO}$. Vértice reto, com cantos arredondados. VOL $0,05 \times \mathrm{HE}$.

Mesosomo: dorso torácico coriáceo; notáulices completas, retas, convergentes e largas atrás, distantes uma da outra atrás $1,0 \mathrm{x}$ suas larguras; sulcos parapsidais finos e retos, ausentes no terço anterior do mesoscuto; sulcos escutelares profundos, extremidades pouco dilatadas e arqueadas para trás (Fig. 9). Disco propodeal 1,5 x mais largo que longo, com cinco carenas discais fortes, carena mediana completa, carenas paramedianas convergentes atrás, atingindo a carena mediana, espaços entre as carenas discais com estrias; parte posterior do disco com estrias longitudinais curtas, ângulo posterior foveolado, disco côncavo em perfil, parte lateral com fóvea estriada, alongada, 3,0 x mais longa que larga; declividade do propódeo com carena mediana, parte superior rugosa e inferior estriada; lateral do propódeo com estrias fracas (Fig. 14). Mesopleura pouco globosa vista de cima, coriácea, brilhante, fóvea inferior rasa, aberta atrás (Fig. 19). Pleurosterno separado da mesopleura por uma fóvea longa, profunda. Fêmures anterior e mediano 
$2,1 \times$ mais longos que largos. Garras tarsais trífidas, o primeiro dente largo e arredondado, o segundo truncado e o terceiro curvo e pontiagudo.

Metasomo: polido e brilhante. Hipopígio com espinho mediano $0,54 \mathrm{x}$ seu comprimento, margem posterior estreita e com cova mediana profunda. Genitália (Figs. 27-28): parâmero alongado, ápice dilatado e arredondado; margens ventral e dorsal retas, base menos desenvolvida que o ápice; volsela com cúspide menos longa que o parâmero, reta e de ápice arredondado, margem dorsal na metade apical; dígito um pouco mais baixo que a cúspide; edeago alargando-se gradualmente até a base arredondada, na mesma altura do dígito; apodema com base dilatada.

Material examinado: Holótipo: macho, BRASIL, Amazonas, Manaus, Reserva Ducke, 17.VII.1992, armadilha adesiva, $2 \mathrm{~m}$, J. Vidal \& J. Vidal col (INPA). Parátipos: 2 machos, BRASIL, Amazonas, Manaus, Reserva Ducke, 617.VII.1992, armadilha adesiva, $2 \mathrm{~m}$, J.Vidal \& J.Vidal col. (INPA).

Variações. WH 1,28-1,29 x LH; WF 0,69-0,70 x WH; WF 1,46-1,47 x HE; OOL $0,72-0,75 \times$ WOT. Disco propodeal 1,21-1,33 x mais largo que longo; fêmur anterior $1,66-2,20 \mathrm{x}$ mais longo que largo; mesopleura reta; segmentos antenais com processos pectinados um pouco menores onde são $0,21-0,25 \times$ menos longos que os próprios segmentos (segmento IX).

Etimologia: nome refere-se ao parâmero largo.

\section{Rhabdepyris (Chlorepyris) pectinatus sp. nov.}

(Figs. 5, 10, 15, 20, 29-30)
Descrição. Macho: comprimento do corpo 4,29 mm; LFW 2,05 mm.

Cor: corpo preto; palpos, antenas e mandíbulas castanho-claros, clípeo preto; pernas castanhas, enfuscadas, com coxas pretas, asas hialinas.

Cabeça (Fig. 5): mandíbulas com cinco dentes apicais, o ventral mais agudo e maior que os demais. Clípeo curto, com carena mediana completa, reta de perfil. Razão entre os quatro primeiros segmentos antenais de 19:10:5:10; segmentos antenais VIIXII com processos finos, muito desenvolvidos, retos, que nascem na face externa da porção distal e são maiores nos segmentos medianos (segmentos VIII-XI), 1,36 x mais longos que o próprio segmento (segmento IX). Fronte fracamente coriácea, brilhante, com pontuações pequenas e esparsas. WH 1,10 x LH, WF $0,65 \times$ WH, WF $1,33 \times \mathrm{HE}$, OOL $0,8 \times$ WOT, ângulo frontal do triângulo ocelar obtuso, ocelo posterior distante da crista do vértice 0,15 $x$ DAO. Vértice reto, com cantos arredondados. VOL $0,18 \times \mathrm{HE}$.

Mesosomo: dorso torácico coriáceo; notáulices completas, retas, convergentes e largas atrás, distantes uma da outra atrás um pouco mais do que suas larguras; sulcos parapsidais rasos e ligeiramente arqueados, ausentes no terço anterior; sulcos escutelares profundos, extremidades arqueadas para trás (Fig. 10). Disco propodeal $1,56 \times$ mais largo que longo, com cinco carenas discais fortes, carena mediana completa, carenas paramedianas convergentes atrás, atingindo a carena mediana, 
espaços entre as carenas discais com estrias; parte posterior do disco com estrias longitudinais curtas, ângulo posterior foveolado, disco côncavo em perfil, parte lateral com fóvea estriada, alongada, 3,6 x mais longa que larga; declividade do propódeo estriada, com carena mediana; lateral do propódeo com estrias inclinadas (Fig. 15). Mesopleura globosa vista de cima, fracamente coriácea, com fóvea inferior aberta atrás, pouco profunda (Fig. 20). Pleurosterno separado da mesopleura por uma fóvea longa, profunda. Fêmur anterior 2,0 x tão longo quanto largo, mediano 3,0 x. Garras tarsais trifidas, o primeiro dente largo e arredondado, o segundo truncado e o terceiro curvo e pontiagudo.

Metasomo: polido e brilhante. Hipopígio com espinho mediano $0,52 \mathrm{x}$ o seu comprimento, margem posterior estreita, com cova mediana profunda. Genitália (Figs. 29-30): parâmero com ápice inclinado, quase reto, margens ventral e dorsal retas; volsela com cúspide mais baixa que o parâmero, quase reta, de ápice arredondado; dígito menor que a cúspide; edeago em forma de garrafa, alargando-se gradualmente até a base subangulada, um pouco mais baixo do que a cúspide; apodema pouco dilatado.

Material examinado. Holótipo: macho, BRASIL, Amazonas, Manaus, Reserva Campina, 19.VI.1992, armadilha adesiva, $1 \mathrm{~m}$, J. Vidal \& J. Vidal col. (INPA), Parátipos: 5 machos. BRASIL, Amazonas, Manaus, 2 machos, Reserva Ducke, 17.VII.1992, armadilha adesiva, 1-2 m, J. Vidal \& J. Vidal col. (INPA);
1 macho, Reserva 1112, 26.II.1985, armadilha Malaise, B. Klein col. (INPA); Rondônia, Reserva JiParaná Gleba, 25-28.II.1983, J. Arias col. (OSUC); Mato Grosso, 1 macho, X.1974, armadilha Malaise; M. Alvarenga col. (CNCI).

Variações. WH 1,21-1,36 x LH; WF $0,68-0,72$ x WH; WF $1,39-1,48$ x HE; OOL 0,82-0,96 x WOT. Disco propodeal $1,26-1,56 \times$ mais largo que longo; fêmur anterior 1,89-2,31 $\mathrm{x}$ mais longo que largo; segmentos antenais com processos pectinados finos, muito desenvolvidos, 0,90$1,75 \mathrm{x}$ mais longos que os próprios segmentos (segmento IX).

Etimologia: nome refere-se aos processos pectinados longos das antenas.

\section{AGRADECIMENTOS}

Ao J. A. Rafael (INPA) pelo empréstimo do material estudado e ao setor de Genética (UFES) pelo empréstimo da câmara-clara do microscópio.

\section{Bibliografia citada}

Azevedo, C. O. 1999. On the Neotropical Rhabdepyris Kieffer (Hymenoptera, Bethylidae) of the subgenus Chlorepyris. Revista Brasileira de Zoologia 16(3): 887-897.

Evans, H. E. 1965. A Revision of the Rhabdepyris in the Americas (Hymenoptera, Bethylidae). Bulletin of Museum of Comparative Zoology 133(3): 68-151.

Harris, R. A. 1979. A glossary of surface sculpturing. Occasional Papers in Entomology 28:1-31.

Vargas-Rojas, J. M. 2001. Dos especies nuevas Rhabdepyris (Hymenoptera, Bethylidae) de Colombia. Iheringia, série Zoologia, 90:133-139.

Aceito para publicação em 28/11/2001 

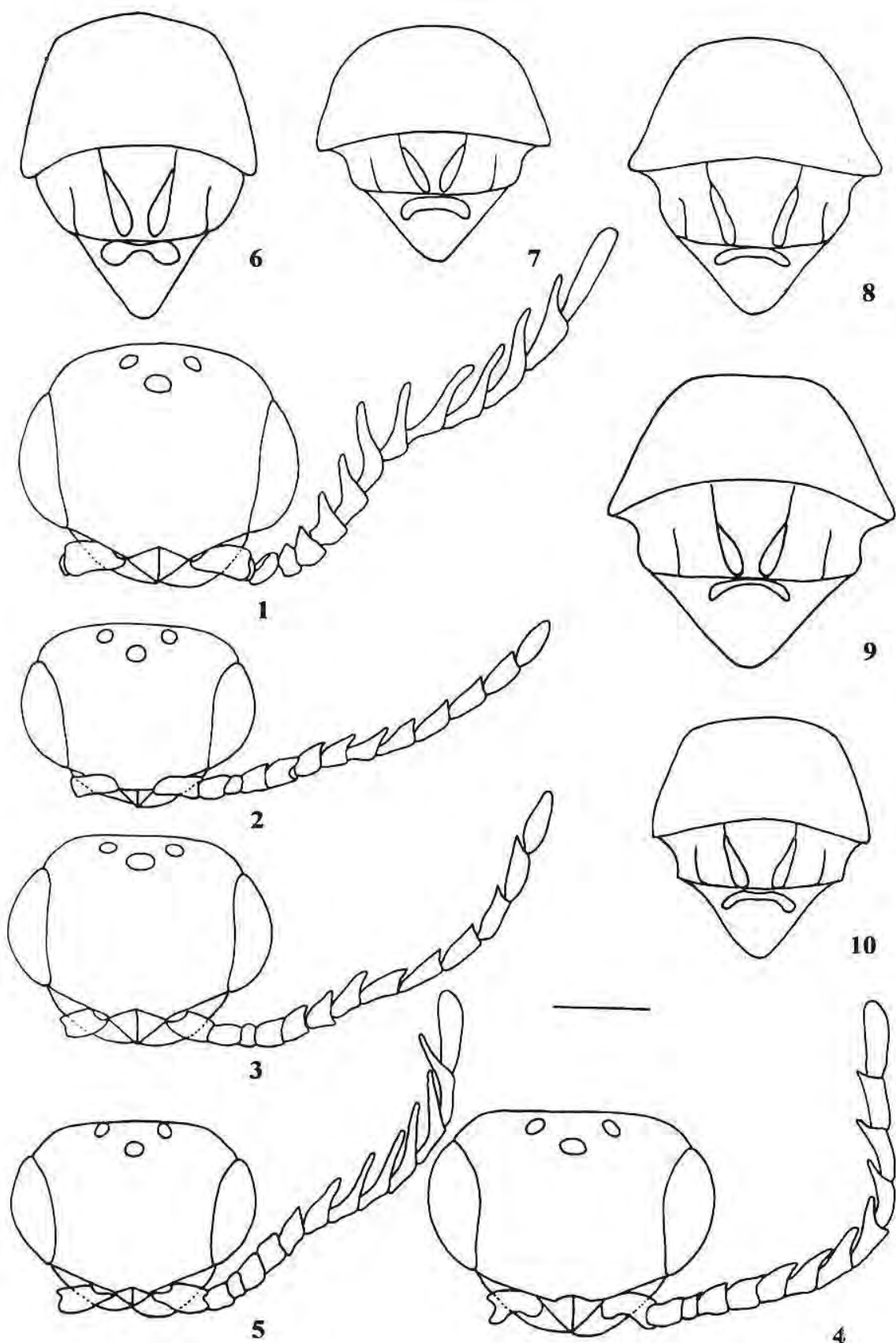

Figuras 1-10. 1-5. Cabeça, vista dorsal, 1. R. (C). opistolatus, 2. R. (C). longimerus, 3. $R$. (C).pleurorrectus, 4. R. (C). latimerus, 5. R. (C). pectinatus; 6-10. Tórax, vista dorsal, 6. $R$. (C). opistolatus, 7. R. (C). longimerus, 8. R. (C).pleurorrectus, 9, $R_{*}(C)$. latimerus, 10. $R$. (C). pectinatus, $($ escala $=0,32 \mathrm{~mm})$. 


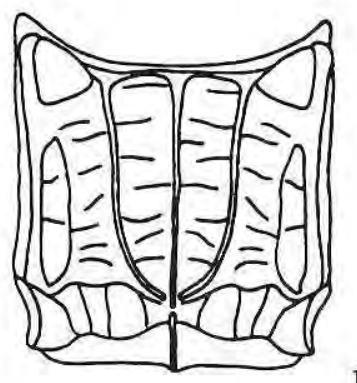

11

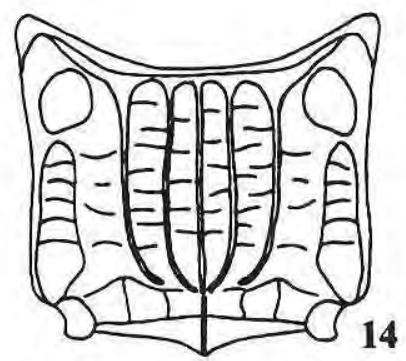

14

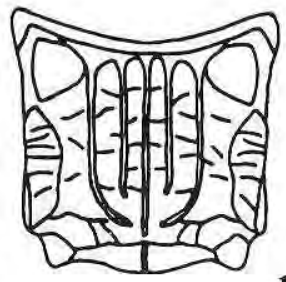

12

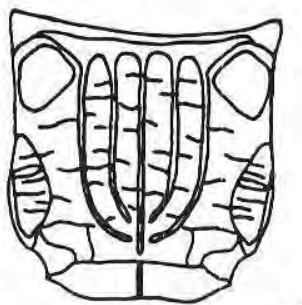

13

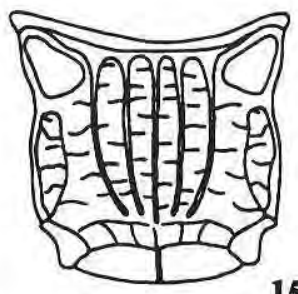

15

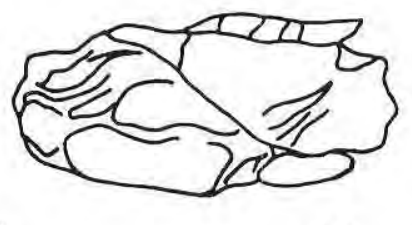

20
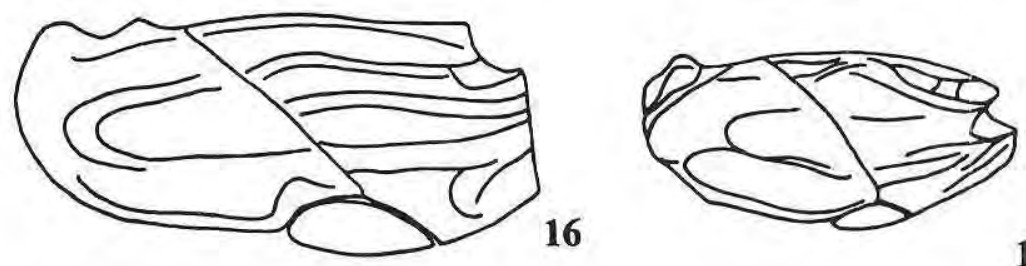

17

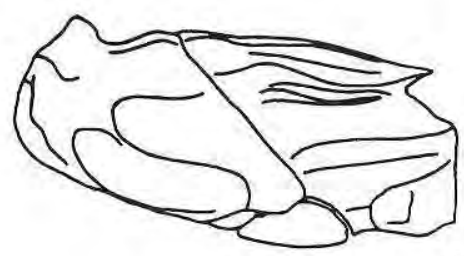

18

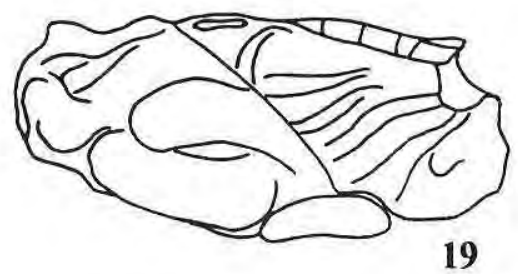

Figuras 11-20. Disco propodeal, vista dorsal, 11, $R .(C)$. opistolatus, 12. $R$. (C). longimerus, 13. $R$. (C).pleurorrectus, 14.R. (C). latimerus, 15.R. (C). pectinatus, 16-20. Mesopleura e própodeo, vista lateral, 16. $R$. (C), opistolatus, 17. $R$. (C). longimerus, 18. R. (C).pleurorrectus, 19. $R$. (C). latimerus, 20. R. (C). pectinatus. (escala $=0,32 \mathrm{~mm})$. 


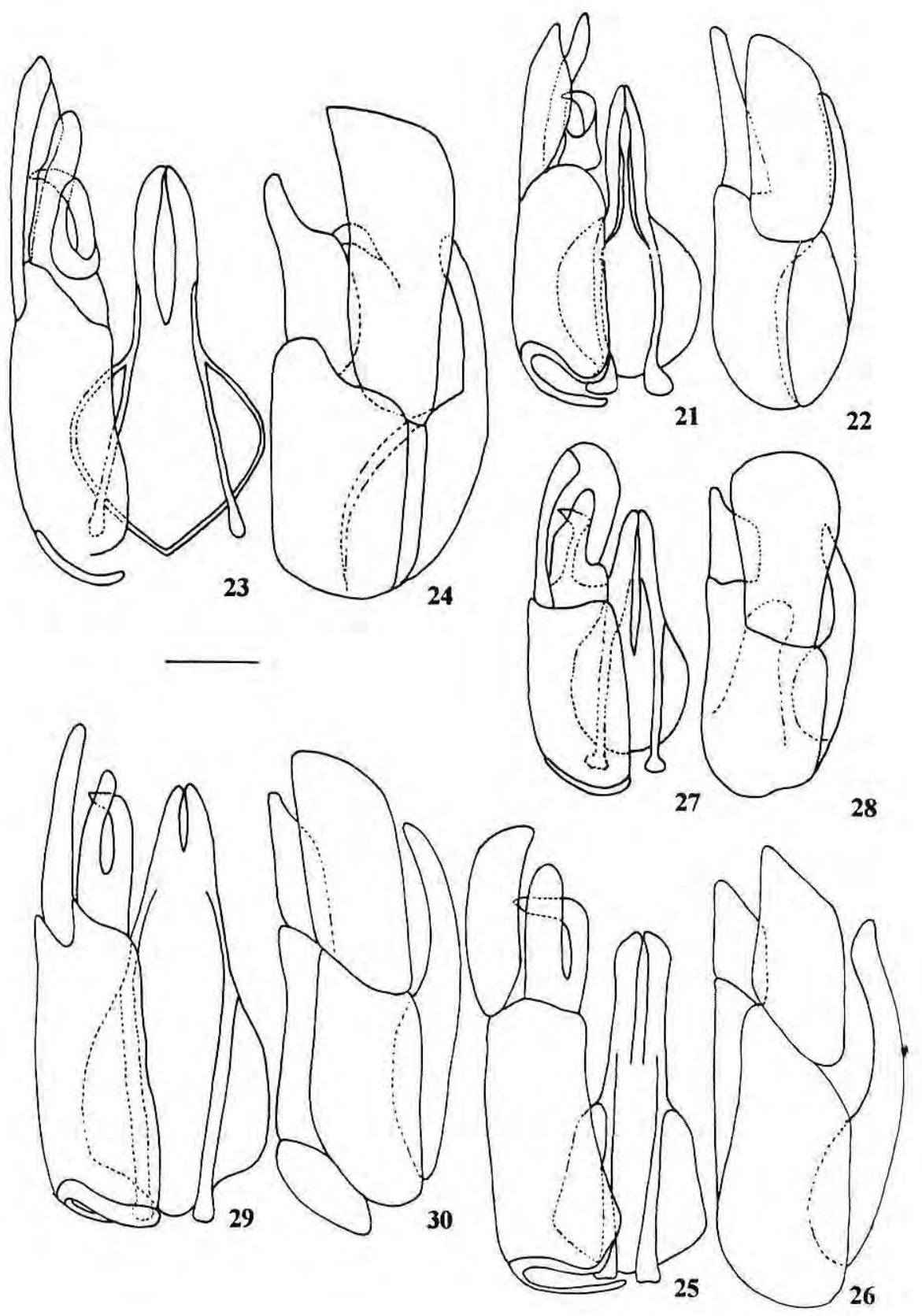

Figuras 21-30. Genitália, vista dorsal e lateral. 21-22. $R$. (C). opistolatus, 23-24. $R$. (C). longimerus, 25-26, $R$. (C).pleurorrectus, 27-28. $R$. (C). latimerus, 29-30. $R$. (C). pectinatus. $($ escala $=123 \mathrm{~mm})$. 